\title{
Micro-spectroscopic study of the degradation of Scandia and Ceria Stabilized Zirconia electrolytes in Solid Oxide Electrolysis Cells
}

\section{A. Laguna-Bercero and V. M. Orera}

Instituto de Ciencia de Materiales de Aragón, ICMA, CSIC - Universidad de Zaragoza, Pedro Cerbuna 12, 50009 Zaragoza, Spain

Corresponding author: malaguna@unizar.es

\begin{abstract}
Degradation is one of the main limitations of Solid Oxide Electrolysers (SOEs) which has been frequently related to the reduction of the electrolyte at the fuel electrode side and also to anomalous high values of oxygen chemical potential, $\square$ o2, within the electrolyte near to the oxygen electrode side. In the present work we have studied the variation of the electrolyte reduction state across the electrolyte thickness using spectroscopic techniques when the cell is operated under electrolysis mode. The experiments have been performed in two different $10 \mathrm{Sc} 1 \mathrm{CeSZ}\left(10 \mathrm{~mol} \%\right.$ of $\mathrm{Sc}_{2} \mathrm{O}_{3}$ and $1 \mathrm{~mol} \%$ of $\mathrm{CeO}_{2}$ doped zirconia) electrolyte-based cells before and after electrolysis operation up to voltages of 2.8 and $1.8 \mathrm{~V}$, respectively. Spatially resolved vibrational and $\mathrm{Ce}^{3+}$ electronic micro-Raman spectroscopy and $\mathrm{Er}^{3+}$ luminescence spectroscopy provides information about the structural changes and defect state along the electrolyte thickness. Whereas the cell remains unaltered when operating at voltages below $1.8 \mathrm{~V}$, degradation was observed for the cell operated at voltages over $2 \mathrm{~V}$, and the degradation is also increasing with the operation time. Different transformations in the 10Sc1CeSZ electrolyte have been observed. Crystalline structure change from cubic to


rhombohedral, firstly appearing at the region near the Ni-YSZ electrode, was detected. The structure change has been further corroborated by XRD studies. The reduction of the electrolyte, as evidenced by the presence of $\mathrm{Ce}^{3+}$, was clearly observed in the electronic micro-Raman spectra. Inhibition of $\mathrm{Er}^{3+}$ luminescence has been associated to the presence of oxygen vacancy defects resulting from zirconia reduction. The profile of the defect distribution and structure change shows that in a thin electrolyte layer of less than $20 \mu \mathrm{m}$ adjacent to the oxygen electrode the electrolyte remains unaltered.

Keywords: Solid oxide steam electrolyser, hydrogen production, SOFC, SOEC, Scandia and Ceria stabilized Zirconia, Raman spectroscopy

\section{Introduction}

Zirconia codoped with scandia and ceria (10Sc1CeSZ) is an excellent ionic conductor at temperatures lower than the well-known studied YSZ. Addition of small amounts of Ceria stabilizes the cubic phase down to RT avoiding the martensitic cubic to rhombohedral phase transition (volume change of $0.15 \%$ ), that takes place at around $600^{\circ} \mathrm{C}$ for the $10 \mathrm{Sc} 1 \mathrm{CeSZ}$. As a consequence, $10 \mathrm{Sc} 1 \mathrm{CeSZ}$ has been proposed as an electrolyte in solid oxide electrolysis cells (SOECs) for hydrogen production at intermediate temperatures $[1,2]$. Apart from lowering the operation temperature when using 10Sc1CeSZ as an alternative to YSZ electrolytes, another advantage is the increase of the electronic conductivity due to the presence of the ceria codopant. According to Virkar model for electrolyte degradation in SOECs [3], increasing the electronic conductivity of the electrolyte decreases the oxygen partial pressure at the 
electrolyte oxygen electrode interface and thus the tendency to delamination of the oxygen electrode. Delamination of the oxygen electrode at the electrolyte interface is probably the main cause of failure in YSZ based electrolysers [4,5]. However, degradation of $10 \mathrm{Sc} 1 \mathrm{CeSZ}$ based cells after electrolysis operation has been previously reported by microstructural studies, AC impedance and XRD experiments [6] Similarly to situation in cells with YSZ electrolytes, electroreduction of the electrolyte $[7,8]$ and delamination of the oxygen electrode under electrolysis operation [9] is also a matter of concern here. In addition, $10 \mathrm{Sc} 1 \mathrm{CeSZ}$ electrolyte degradation may also be caused by changes in the crystal structure of zirconia and also in the valence state of cerium. In fact, ionic conductivity degradation and reduction of $\mathrm{Ce}^{4+}$ ions in reducing conditions have also been recently reported in $10 \mathrm{Sc} 1 \mathrm{CeSZ}$ samples [10]. Since the electrolyte is under strong reducing conditions at the fuel electrode side and under oxidizing conditions at the oxygen electrode side, a large gradient in the reduction state and/or degradation across the electrolyte thickness is expected.

The double purpose of the present study is to determinate the limits for stable SOEC operation with $10 \mathrm{Sc} 1 \mathrm{CeSZ}$ electrolytes and also to discover the origin of cell degradation. Valuable information about the spatial distribution of the degradation and hence on the details of the microscopic origin for this degradation could be obtained by spatially resolved spectroscopical methods as well as by Electron Microscopy and Microanalysis techniques. Raman spectroscopy is a useful tool to study the polymorphs of zirconia. By this technique, it is possible to distinguish between the monoclinic, tetragonal and cubic phases in YSZ [11,12]. This technique allows us the study of structure changes derived from aging effects and thermal evolution of Sc-doped zirconia [13]. In addition Micro-Raman technique provides the spatial resolution needed to study 
the transformations along the transverse-cross section of the cell. Appart from the structure information given by the vibrational Raman spectra, resonant electronic Raman scattering could be also used to study the $\mathrm{Ce}^{4+} \leftrightarrow \mathrm{Ce}^{3+}$ conversion in cerium doped zirconia. This could be done by monitoring the presence of the $2086 \mathrm{~cm}^{-1}$ peak corresponding to the ${ }^{2} \mathrm{~F}_{7 / 2} \rightarrow{ }^{2} \mathrm{~F}_{5 / 2} \mathrm{Ce}^{3+}$ electronic transition [14].

Regarding to the $\mathrm{ScSZ}$ phase changes, the phase diagram of the $\mathrm{ZrO}_{2}-\mathrm{Sc}_{2} \mathrm{O}_{3}$ system is more complex than other more studied zirconia systems such as $\mathrm{ZrO}_{2}-\mathrm{Y}_{2} \mathrm{O}_{3}$ or $\mathrm{ZrO}_{2-}$ $\mathrm{CaO}$ systems. As the $\mathrm{Sc}_{2} \mathrm{O}_{3}$ content is increased, intermediate phases such as the rhombohedral $\beta$-phase $\left(\mathrm{Sc}_{2} \mathrm{Zr}_{7} \mathrm{O}_{17}\right)$ could be formed. The formation of this phase is a consequence of the presence of oxygen vacancies [15]. Other metastable phases such as the $\gamma$-phase $\left(\mathrm{Sc}_{2} \mathrm{Zr}_{5} \mathrm{O}_{13}\right)[15,16], \delta$-phase $\left(\mathrm{Sc}_{4} \mathrm{Zr}_{3} \mathrm{O}_{12}\right)$ [15] or even single crystals of the rhombohedral $\mathrm{Zr}_{50} \mathrm{Sc}_{12} \mathrm{O}_{118}$ phase [17] have been described.

Raman spectra of the $\beta$-phase were firstly reported by Tietz et al. [18]. They observed that the modes around $600 \mathrm{~cm}^{-1}$ (that corresponds to the cubic zirconia phase) are shifted to lower wavenumbers peaking at around $580 \mathrm{~cm}^{-1}$, also presenting a triplet structure. Similar observations were found by Fujimori et al. [19]. These same authors observed in-situ the transformation from the $\beta$-phase to the cubic phase by annealing up to $750{ }^{\circ} \mathrm{C}[20]$.

In the present work we have performed structural and defect studies of 10Sc1CeSZbased cells before and after electrolysis under different operating conditions, as stated above. Using the micro-Raman technique, transformation and reduction of the 10Sc1CeSZ electrolyte after electrolysis operation has been measured with high spatial resolution along the electrolyte thickness profile. After high voltages and long operation times it was observed that both zirconia phase transformation from cubic to $\beta$-phase and 
electrolyte reduction takes place. Both effects are spatially related and takes mainly place through all the electrolyte thickness except for the electrolyte region which is very near to the oxygen electrode.

\section{Experimental}

\subsection{Cell fabrication and electrochemical analysis}

Ni-YSZ (electrode)/10Sc1CeSZ half-cells provided by Kerafol Gmbh, Germany, were used for the present studies. $\mathrm{La}_{0.8} \mathrm{Sr}_{0.2} \mathrm{MnO}_{3-\delta}$ (lanthanum strontium manganite)-YSZ ink (50/50 weight \%) (Fuelcell Materials, USA) was deposited on top of the electrolyte of half cells by screen-printing, dried in air at $100^{\circ} \mathrm{C}$ and then sintered in air at $1050^{\circ} \mathrm{C}$. For the present study we have analyzed two analogue cells: The first cell (LSM01) was operated at severe conditions (polarized at maximum voltage of $2.8 \mathrm{~V}$ for about 72 hours under electrolysis operation) whereas the second cell (LSM02) was only polarized up to $1.8 \mathrm{~V}$ for a total period under SOEC operation of 12 hours.

Typical Area Specific Resistance (ASR) values obtained from $j$-V (current densityvoltage) curves at $800{ }^{\circ} \mathrm{C}$ in SOEC mode are 0.96 and $0.93 \Omega \mathrm{cm}^{2}$ for the LSM01 and LSM02 cells, respectively. Detailed information regarding the electrochemical performance of the cells could be found in refs. 6 and 21, and are also summarized in table 1 .

\subsection{Microstructural and structural analysis after electrolysis operation}

After SOEC operation, transverse-cross sections of the cells were cut and polished. Scanning Electron Microscopy (SEM) experiments were performed under an accelerating voltage of $20 \mathrm{kV}$ using a JEOL 6400 SEM (JEOL, USA) fitted with Oxford 
Instruments INCA energy dispersive analytical system (EDS) for elemental x-ray analysis.

Both Raman and Luminescence spectra were locally measured across a transverse-cross sections of the cells using an optical spectrometer (Model XY, DILOR, Lille, France) coupled to an optical microscope. The spectra were collected at room temperature in a backscattering geometry using a triple $0.5 \mathrm{~m}$ monochromator with $\mathrm{CCD}$ detector with spectral resolution of $0.3 \mathrm{~cm}^{-1}$. Microscope objectives of x50 and x 100 give a maximum lateral resolution of about $2 \mu \mathrm{m}^{2}$. The same set-up was used to measure the cerium doped YSZ single crystal samples. For comparison purposes cerium doped single crystal YSZ samples (Ceres Co., USA) were also used in this work. The composition of these single crystals was (in wt\%) $\mathrm{Y}_{2} \mathrm{O}_{3}: 16.8, \mathrm{CeO}_{2}: 0.42, \mathrm{ZrO}_{2}: 82.78$. They were measured in both the oxidized state (white transparent) and after reduction (orange transparent) at $700-1000{ }^{\circ} \mathrm{C}$ in flowing $\mathrm{H}_{2}-\mathrm{N}_{2}$ mixture $\left(5 \% \mathrm{H}_{2}\right)$. The spectra were measured from 100 to $2500 \mathrm{~cm}^{-1}$ from exciting line. In order to distinguish between phonon-Raman, electronic-Raman and luminescence, three different lines of an $\mathrm{Ar}^{+}$-ion laser, 488, 496.5 and $514.5 \mathrm{~nm}$ were used for excitation.

In order to study the crystal phase transformation occurring in the electrolytes after SOEC operation, the electrodes from the operated cell were carefully removed by mechanical polishing to perform X-ray diffraction (XRD) of the electrolytes. XRD was carried out using a Philips PW1700 series diffractometer with $\mathrm{Cu} \mathrm{K}_{\alpha}$ radiation.

\section{Results and discussion}

\subsection{Defect states and degradation}

As we could not found any data about the defect structure in 10Sc1CeSZ we have been 
based on previous studies performed in pure and Cerium doped YSZ single crystals.

In the unreduced state, $10 \mathrm{Sc} 1 \mathrm{CeSZ}$ is an insulator with a large amount of oxygen vacancies in the zirconia lattice resulting from doping with $\mathrm{Sc}_{2} \mathrm{O}_{3}$.

$\mathrm{SC}_{2} \mathrm{O}_{3} \rightarrow 2 \mathrm{SC}_{\mathrm{ZP}}+\mathrm{V}_{\mathrm{n}}^{-}+3 \mathrm{O}_{0}^{\mathrm{X}}$

The concentration of extrinsic oxygen vacancies is about $\left[\bar{V}_{\mathrm{n}}^{-}\right] \approx 3 \times 10^{21} \mathrm{~cm}^{-3}$ giving an ionic conductivity $\sigma_{\mathrm{i}} \cong 0.322 \mathrm{Scm}^{-1}$ [22]. For a wide range of oxygen partial pressures, the concentration of oxygen vacancies is expected to be nearly constant, and ionic conductivity overwhelms electronic conductivity. At low oxygen partial pressures, electrons are trapped at deep states. In particular for $\mathrm{p}_{\mathrm{O} 2}<10^{-20}$ bars at $700^{\circ} \mathrm{C}$ the following reactions occur [23]

$0_{0}^{\mathrm{N}}-1 / 2 \mathrm{O}_{2}(\mathrm{~g}) \rightarrow \mathrm{V}_{\mathrm{n}}^{-}+2 \mathrm{e}$

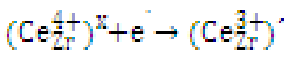

being $\left[\mathrm{Ce}^{4+}\right] \approx 3 \times 10^{20} \mathrm{~cm}^{-3}$ for the unreduced zirconia.

In YSZ, electrons are trapped at $\mathrm{Ce}^{3+}$ at about $2.5 \mathrm{eV}$ below the conduction band, $0.9 \mathrm{eV}$ over the Fermi level in the unreduced state. The otherwise white zirconia becomes orange coloured due to the $4 \mathrm{f}^{1} \leftrightarrow 5 \mathrm{~d}^{1}$ parity allowed crystal field transitions of the $\mathrm{Ce}^{3+}$ ion [14]. The kinetics of the $\mathrm{Ce}^{4+}$ to $\mathrm{Ce}^{3+}$ oxido-reduction processes in ceria-doped zirconia single crystals has been previously reported $[23,14]$.

Electron traps other than $\mathrm{Ce}^{3+}$ have been identified in severely thermochemically reduced zirconia. In particular, there are intrinsic defects giving rise to blackening and electronic conduction. These defects (called C-defects) produce an intense and broad absorption band (extinction coefficient $\alpha \approx 65 \mathrm{~cm}^{-1}$ ) centred at about $480 \mathrm{~nm}$ and also an increase of the electronic conductivity. Both have been associated with the formation of oxygen vacancy related electrons trap states, placed at about $1.1 \mathrm{eV}$ below the 7 
conduction band, $2.2 \mathrm{eV}$ above unreduced state Fermi level [24]. This "blackening" effect is reversible and does not involve permanent degradation of the electrolyte. Energy level diagrams for these electronic defects can be found in refs. [25,23] indicating that, as the electrolyte reduction proceeds the electronic Fermi level goes up in the diagram and $\mathrm{Ce}^{3+}$ defects first, and them the intrinsic electron trapped defects are sequentially produced. $\mathrm{Ce}^{3+} / \mathrm{Ce}^{4+}$ transformation occurs at $\mathrm{p}_{\mathrm{O} 2} \approx 10^{-16}-10^{-17}$ at $700^{\circ} \mathrm{C}$ [23].

The electronic conductivity as a function of the oxygen partial pressure and temperature of YSZ is empirically given by [26]

$$
\sigma_{\mathrm{e}} \cong 1.31 \times 10^{7} \exp (-3.88 \mathrm{eV} / k T) p_{\mathrm{m} 2}^{-1 / 4}
$$

where $k$ is the Boltzmann constant, $T$ the absolute temperature and $p_{\mathrm{O} 2}$ the oxygen partial pressure. It is remarkable that eq. 4 predicts the electronic conductivity at $800^{\circ} \mathrm{C}$, which is equal to $\sigma_{\mathrm{I}}=0.1 \mathrm{Scm}^{-1}$ for $p_{\mathrm{O} 2} \approx 2 \times 10^{-38}$ bars. In the electrochemical cell, the oxygen partial pressure can be related with Nernst potential. For cells operated at 800 ${ }^{\circ} \mathrm{C}$ under air atmosphere at the oxygen electrode side, the Nernst potential for equal electronic and ionic conductivity is about $2.0 \mathrm{eV}$.

Zirconia decomposition takes place at oxygen partial pressures of $\ln \left[p_{\mathrm{O} 2}\right]=\Delta G / R T$. Using the free energy of formation for zirconia $\Delta G=-894.6 \mathrm{~kJ} / \mathrm{mol}$ we obtain a very low oxygen partial pressure of $2.82 \times 10^{-44}$. Zirconia decomposition involves the presence of metallic $\mathrm{Zr}$ particles, being this an irreversible process. The onset voltage value at the electrolyte for zirconia decomposition is then $2.285 \mathrm{~V}$, where these estimations correspond to open circuit situation. Applied cell voltages differ from this value due to electrode polarization effects and mixed conduction. For the present studies, we have operated the cells well above and below this decomposition voltage. 


\subsection{Microstructure and structure analysis}

In figure 1 we observe SEM images for the LSM01 sample before (a) and after (b) severe electrolysis operation. It is remarkable that there has been an increase of porosity from the centre towards the oxygen electrode side of the $10 \mathrm{Sc} 1 \mathrm{CeSZ}$ electrolyte. As observed by other authors, when a SOE cell is operated at extreme conditions (at high current densities), degradation is generally attributed to ohmic degradation [27] and these authors observed that degradation occurs in the form of voids proliferating along the grain boundaries of the electrolyte. Similar findings were recently reported on microtubular YSZ-based SOE cells also operated at high current densities [28]. EDS microanalysis were also performed along the section of the electrolyte, as shown in the micrograph (1b). Although the resolution of the technique does not allow accurate oxygen quantification, we have observed that there is a clear tendency to oxygen contents lower than those corresponding to stoichiometric 10Sc1CeSZ all along the ScSZ electrolyte, except for a narrow region of about 15-20 microns next to the oxygen electrode. In addition, in porous regions of the electrolyte (see fig. 1b) we have observed higher oxygen contents. We believe that there is a tendency for the formation of oxygen voids at zirconia porous grain boundaries. Formation of oxygen filled voids in reduced zirconia was previously reported by other authors [27,28].

In figure 2 we illustrate the crystal structure of the electrolytes for the LSM01 and LSM02 samples after SOEC operation and electrode removal. The XRD pattern for the LSM02 corresponds to cubic 10Sc1CeSZ. However, in the case of LSM01 sample we have observed a two phase mixture of cubic and $\beta$-rhombohedral phases. This could be explained by a partial phase transformation of the zirconia electrolyte from cubic to the rhombohedral $\beta$-phase $\left(\mathrm{Sc}_{2} \mathrm{Zr}_{7} \mathrm{O}_{17-\delta}\right)$. The formation of this low symmetry phase would 
be a consequence of the increase in concentration of oxygen vacancies [15]. On the contrary, from the XRD pattern for the low voltage operated LSM02 cell (fig. 2) we can observe that there is no sign of phase transformation in the electrolyte. The cubic phase for the $10 \mathrm{Sc} 1 \mathrm{CeSZ}$ is maintained after operation.

A typical cross-section for the LSM02 sample is also shown in figure 1 (c). For this cell we do not observe the presence of any microstructure damage in the form of large voids or pores that could indicate electrolyte degradation. We have only observed some pores next to the Ni-YSZ electrode. Contrary to the case of the cell operated at $2.8 \mathrm{~V}$, oxygen content estimated by EDS analysis present values practically constant along the thickness of the electrolyte.

A first consequence of these structural and microstructural studies is that, as for the case of YSZ based cells, 10Sc1CeSZ electrolyte cells should be operated at a maximum voltage of around $2 \mathrm{~V}$.

\subsection{Spectroscopic background}

The spectral features used to study the defect distribution across the electrolyte thickness are now described taken as a reference the well known case of the YSZ:Ce sample. Figure 3 shows the Raman and luminescence spectra measured in a reduced YSZ:Ce single crystal sample at two different exciting wavelengths, 496.5 and 514.5 nm. Considering only the most intense spectral features three different regions can now be distinguished: a region of lattice phonon Raman bands whose peak positions do not depend on exciting wavelength, resonant electronic Raman bands whose peak positions do not depend on the exciting wavelength whereas its intensity changes according to the absorption band shape and finally, luminescence bands which appear at a fixed 
detection wavelength. All three spectral regions should be used in this study to obtain local information about the crystallography and reduced defect state of the electrolyte. The density of states-like spectrum with bands at 137, 275 and $600 \mathrm{~cm}^{-1}$ observed for any excitation line are assigned to the Raman spectra of the $\mathrm{T}_{2 \mathrm{~g}}\left(\mathrm{O}_{\mathrm{h}}{ }^{5}\right)$ mode of the YSZ matrix in good agreement with previous studies $[29,30]$. The narrow and intense band at $2086 \mathrm{~cm}^{-1}$ was previously identified by Orera et al. [14] as a $\mathrm{Ce}^{3+}$ electronic Raman peak. In particular this peak is associated to the ${ }^{2} \mathrm{~F}_{7 / 2} \rightarrow{ }^{2} \mathrm{~F}_{5 / 2}$ electronic transition within the $4 \mathrm{f}^{1}$ configuration of $\mathrm{Ce}^{3+}$ and its intensity is anomalously large due to a resonant effect by the excitation of the $4 \mathrm{f} \rightarrow 5 \mathrm{~d}$ transition of the $\mathrm{Ce}^{3+}$ ion at about $459 \mathrm{~nm}$. Both lattice phonon and electronic Raman spectra are equally shifted from the excitation light regardless of the excitation wavelength. However, due to the resonant effect, the intensity of the $2086 \mathrm{~cm}^{-1} \mathrm{Ce}^{3+}$ electronic Raman band increases when decreasing the laser excitation wavelength. It is also remarkable for the following discussion that both the $\mathrm{Ce}^{3+}$ absorption and that of the intrinsic defects appearing in the strongly reduced samples, almost coincide in position.

When the excitation laser line is tuned to 488 or $514.5 \mathrm{~nm}$, two groups of intense bands appear in the 19.000 and $18.000 \mathrm{~cm}^{-1}$ region. In the case of $514.5 \mathrm{~nm}$ excitation, those groups appear at about 400 and $1200 \mathrm{~cm}^{-1}$ from exciting light. These bands correspond to the emission of $\mathrm{Er}^{3+} . \mathrm{Er}^{3+}$ appears in the YSZ single crystals as an unwanted impurity which accompanies to the cerium doping and was previously studied by Merino et al. [31]. According to this study, the $514.5 \mathrm{~nm}$ laser line excites the ${ }^{2} \mathrm{H}_{11 / 2} \mathrm{Er}^{3+}$ level. The relaxation takes place via radiative transitions to the ${ }^{4} \mathrm{I}_{15 / 2}$ ground level or via non radiative population and further emission from the intermediate ${ }^{4} S_{3 / 2}$ level. Analogously, 488nm excitation induces the population of the ${ }^{4} \mathrm{~F}_{7 / 2}$ level and similar 
emission bands. Fortunately, the $496.5 \mathrm{~nm}$ laser line does not excite any $\mathrm{Er}^{3+}$ level thus obtaining a spectrum free of the large $\mathrm{Er}^{3+}$ emission bands. In summary, the intensity of the $2086 \mathrm{~cm}^{-1}$ could be used as a measurement of the processes described by eqs. 2 and 3 , being the proof for the early stages of electrolyte reduction. As the reduction takes place, electron trapped intrinsic defects are produced. The presence of these defects can be monitored by its absorption band but in this case it is very difficult to perform such kind of experiments and also with spatial resolution in a cell cross-section. However, we can indirectly detect the presence of these defects by monitoring the decrease in $\mathrm{Er}^{3+}$ luminescence intensity and also in the $\mathrm{Ce}^{3+}$ resonant electronic Raman signal induced by the strong absorption associated to their presence.

Unfortunately, we have still not been able to develop a quantitative analysis using the methods described above and the results explained here are only qualitative.

\subsection{Spectroscopic analysis of the cells after SOEC operation}

In figure 4 we show the spectra of the LSM02 sample (operated up to $1.8 \mathrm{~V}$ ). The spectra taken using the $496.5 \mathrm{~nm}$ laser line show the density of states-like spectrum corresponding to the cubic zirconia phase with the most intense feature in $620 \mathrm{~cm}^{-1}$ and less intense ones at 480, 370 and $150 \mathrm{~cm}^{-1}$. They are assigned to the Raman active lattice phonons of the cubic stabilized zirconia [32,33,34]. The $\mathrm{Er}^{3+}$ emission bands are also observed for the $514.5 \mathrm{~nm}$ excitation. Their positions and relative intensities are rather similar to those of the YSZ single crystal (fig. 3) as it corresponds to $4 \mathrm{f}$ intraconfigurational transitions which are only slightly dependent on the crystal field.

However, when the cell is operated at high voltages in SOEC mode, some dramatic changes in the 10Sc1CeSZ spectrum occurs. These changes take place along the 
electrolyte thickness except for a thin layer close to the oxygen electrode, which is consistent whit our observations from the EDS analysis previously described.

In figure 5 (a) we show the spectra measured at less than $5 \mu \mathrm{m}$ from the fuel electrodeelectrolyte interface for the LSM01 sample. Some noticeable changes have occurred when compared with the spectra of the LSM02 sample (figure 4).

The signals due to $\mathrm{Ce}^{3+}$ so as a broadening and shift towards low energies of the phonon band characteristic of the zirconia lattice are clearly observed. On the other hand, the $\mathrm{Er}^{3+}$ bands almost disappeared.

In figure 5 (b) we show the spectra taken in the same sample close to the oxygen electrode-electrolyte interface. It is observed that in this case the measurements are very similar to those of the LSM02 sample except for the incipient presence of $\mathrm{Ce}^{3+}$ and lower intensity of the $\mathrm{Er}^{3+}$ emissions. The differences in the lattice phonon region between LSM02 (along all the electrolyte thickness) and LSM01 (near both fuel electrode and oxygen electrode interfaces) can be better observed in Figure 6. It is remarkable that LSM02 presents the cubic phase, as well as in the region very near the oxygen electrode for the LSM01 sample. However, the spectrum clearly changes at a region of about $130 \mu \mathrm{m}$ form the Ni-YSZ electrode, where the cubic modes around 615 $\mathrm{cm}^{-1}$ are shifted to lower wavenumbers peaking at around $590 \mathrm{~cm}^{-1}$, which is consistent with the presence of the $\beta$-rhombohedral phase as established by other authors $[18,19]$.

\subsection{Defect concentration across the electrolyte thickness}

The changes in the defect concentration across the electrolyte thickness have been determined taking into account the intensity of the $\mathrm{Ce}^{3+}$ Raman electronic bands (496.5 
$\mathrm{nm}$ excitation) and also the $\mathrm{Er}^{3+}$ emissions (514.5nm excitation), measured using a micro-Raman experimental set-up.

In figure 7 we show the changes in the $\mathrm{Ce}^{3+}$ and $\mathrm{Er}^{3+}$ band intensities. We can observe that both signals are detected neither in the fuel electrode (Ni/YSZ) nor in the oxygen electrode (LSM/YSZ) close to the electrolyte interfaces, presumably due to the strong absorptions of metallic Ni and LSM respectively. The $\mathrm{Ce}^{3+}$ resulting from reaction (3) can be detected from the oxygen electrode interface. Its intensity increases until it reaches a maximum value near the centre of the electrolyte to decrease and disappear near the fuel electrode interface. Nearly opposite is the behavior observed for the intensity of the $\mathrm{Er}^{3+}$ band. It becomes almost zero at the fuel electrode side increasing at about the centre of the electrolyte layer, and reaching the saturation at about 20 microns from the oxygen electrode.

We would also like to relate the obtained results with the model given by Virkar [3], which explains oxygen electrode delamination in SOEC. Taking into account the equilibrium equation involving oxygen ions, oxygen molecules and electrons

$$
1 / 2 \mathrm{O}_{2}(\mathrm{~g})+2 \mathrm{e}^{*} \rightarrow \mathrm{O}^{2-}
$$

which leads to the following relationship between the oxygen ion, oxygen molecule and electron chemical potential

$$
1 / 2 \mu_{\mathrm{O}}^{2-}+2 \mu_{\mathrm{e}}=\mu_{\mathrm{O}}^{2-}
$$

A decrease in $\mu_{\mathrm{e}}$ produces an increase in $\mu_{\mathrm{O} 2}$ and as a consequence in $p_{\mathrm{O} 2 \text {. }}$

Since discussed above, the intensity of the $\mathrm{Er}^{3+}$ and $\mathrm{Ce}^{3+}$ signals are inversely and directly proportional respectively, to the distance from the Fermi level to the bottom of the conduction band. In particular, the presence of $\mathrm{Ce}^{3+}$ indicates that the Fermi level is about $0.9 \mathrm{eV}$ from the centre of the band gap. In addition, a decrease in both $\mathrm{Ce}^{3+}$ and 
$\mathrm{Er}^{3+}$ signals indicates that oxygen vacancy centres are formed and the Fermi level is about $2.3 \mathrm{eV}$ from the centre. Consequently, the concentration of the electron trapped centres is an indirect measure of the electron chemical potential. Since $\mu_{\mathrm{O}}{ }^{2-}$ is essentially constant for an ionic conductor (see eq. 1), a sharp decrease in $\mu_{\mathrm{e}}$ will imply a sudden increase in $\mu_{\mathrm{O} 2}$ and hence in $p_{\mathrm{O} 2}$. This argument could explain why we have observed a high concentration of oxygen molecules from the centre towards the oxygen electrode side of the electrolyte, where the $\mathrm{Er}^{3+}$ signal and thus the concentration of intrinsic defects resulted from the electroreduction process suffer a sudden change. Similar arguments could be applied to explain the change in $\mathrm{Ce}^{3+}$ concentration plotted in figure 7.

Finally, it is interesting to remark the existence of a narrow but convenient layer of insulating electrolyte adjacent to the oxygen electrode, which may assure a high ionic transport number and electrochemical conversion efficiency.

\section{Conclusions}

Degradation for $10 \mathrm{Sc} 1 \mathrm{CeSZ}$ electrolyte based cells has been studied by spatially resolved vibrational and $\mathrm{Ce}^{3+}$ electronic micro-Raman spectroscopy and also $\mathrm{Er}^{3+}$ luminescence spectroscopy. The electrolyte reduction is firstly appearing at the region near the Ni-YSZ electrode and then progressing along the thickness of the electrolyte. This degradation comprises the structure change of the electrolyte from cubic to rhombohedral phase which has been further corroborated by XRD studies. The reduction of the electrolyte, as evidenced by the presence of $\mathrm{Ce}^{3+}$, was clearly observed in the electronic micro-Raman spectra. Degradation was observed for samples that have 
been under high operation voltage for longer times. Electrolyte electroreduction and degradation does not occur when the cell is operated at $1.8 \mathrm{~V}$.

\section{Acknowledgements}

We would like to thank Prof. John Kilner and Dr. Stephen Skinner for their supervision of the electrolysis experiments prior to this study, and Dr. Rosa I. Merino for discussion. We also thank grants no. MAT2009-14324-C02-01, GA-LC-009/2009 and CIT-120000-2007-50 financed by the Spanish Government, DGA-Caixa and Feder program of the European Community for funding the project. MAL-B would also thank the JAE-program (CSIC) for financial support. 


\section{Tables}

Table 1. Summary of the electrochemical analysis for the LSM01 and LSM02 samples. Both samples were tested in SOEC mode at $800{ }^{\circ} \mathrm{C}$ using $70 \% \mathrm{H}_{2} \mathrm{O} / 24 \% \mathrm{~N}_{2} / 6 \% \mathrm{H}_{2}$ in the fuel electrode side and synthetic air in the oxygen electrode side. Voltage and current density correspond to maximum applied values.

\begin{tabular}{|c|c|c|c|c|c|}
\hline Cell & OCV & Voltage & Current & ASR $_{\text {cell }}$ & Total operation \\
name & $(\mathrm{V})$ & $(\mathrm{V})$ & $\begin{array}{c}\text { density } \\
\left(\mathrm{A} . \mathrm{cm}^{-2}\right)\end{array}$ & & \\
\hline LSM01 & 0.865 & 2.8 & 1.821 & 0.96 & 72 \\
\hline LSM02 & 0.850 & 1.8 & 0.498 & 0.93 & 12 \\
\hline
\end{tabular}




\section{Figure captions}

Fig. 1 Polished-cross section SEM images for the LSM01 sample before (a) and after (b) electrolysis operation. Image (c) corresponds to sample LSM02 after SOEC operation. Markers correspond to the analysed areas (EDS and micro-Raman).

Fig. 2 XRD patterns from the 10Sc1CeSZ electrolyte (samples LSM01 and LSM02) after electrolysis polarization. C corresponds to the cubic phase of the $\mathrm{ScSZ}$ and $\beta$ the rhombohedral phase $\left(\mathrm{Sc}_{2} \mathrm{Zr}_{7} \mathrm{O}_{17}\right)$. Impurity peaks correspond to the LSM electrode.

Fig. 3 Spectra of reduced YSZ:Ce single crystal measured using two different excitation laser lines.

Fig. 4 Spectra of the 10Sc1CeSZ electrolyte of the LSM02 sample measured using two different excitation laser lines. Black is measured with $\lambda=514.5 \mathrm{~nm}$ laser line. Red: $\lambda$ $=496.5 \mathrm{~nm}$ laser line

Fig. 5 (a) Spectra of the LSM01 sample taken in the electrolyte at $5 \square \mathrm{m}$ from the electrolyte-anode interface with the 496.5 and $514.5 \mathrm{~nm}$ exciting laser lines; and (b) Spectra of the LSM01 sample taken in the electrolyte at $3 \square \mathrm{m}$ from the electrolytecathode interface with the 496.5 and $514.5 \mathrm{~nm}$ laser lines.

Fig. 6 Raman spectra of 10Sc1CeSZ electrolytes corresponding to LSM02 and LSM01 cells near the fuel electrode and oxygen electrode. Red LSM02, Green LSM01 about 5 $\mu \mathrm{m}$ from the oxygen electrode, Black LSM01 about $5 \mu \mathrm{m}$ from the fuel electrode.

Fig. $7 \mathrm{Ce}^{3+}$ electronic Raman intensity (triangles) and $\mathrm{Er}^{3+}$ emission intensity (squares) measured along the electrolyte thickness in the LSM01 sample, starting from the oxygen electrode interface . 


\section{References}

1 J.E. O’Brien, C.M. Stoots, J.S. Herring, J. Hartvigsen, J. Fuel Cell Sci. Technol., 2006, 3, 213.

2 M.A. Laguna-Bercero, S.J. Skinner, J.A. Kilner, J. Power Sourc., 2009, 192, 126.

3 A.V. Virkar, Int. J. Hydrogen Energy, 2010, 35, 9527.

4 A. Momma, T. Kato, Y. Kaga, S. Nagata, J. Ceram. Soc. Japan, 1997, 105, 369.

5 J.S. Herring, J.E. O’Brien, C.M. Stoots, G.L. Hawkes, J.J. Hartvigsen, M. Shahnam, Int. J. Hydrogen Energy, 2007, 32, 440.

6 M. A. Laguna-Bercero, J. A. Kilner and S. J. Skinner, Chem. Mater., 2010, 22, 1134.

7 J. Schefold, A. Brisse, M. Zahid, J. Electrochem. Soc., 2009, 156, B897.

8 M.A. Laguna-Bercero, R. Campana, A. Larrea, J.A. Kilner, V.M. Orera, Fuel Cells, 2011, 11, 116.

9 J.R. Mawdseley, J.D. Carter, A.J. Kropf, B. Yildiz, V.A. Maroni, Int. J. Hydrogen Energy, 2009, 34, 4198.

10 S. Omar, A. Belda, A. Escardino, N. Bonanos, Solid State Ionics, 2011, 184, 2.

11 N.R. Harlan, R.I. Merino, J.I. Peña, A. Larrea, V.M. Orera, C. González, P. Poza and J. Llorca, J. Am. Ceram. Soc., 2002, 85, 2025.

12 M. Yasima, K. Ohtake, M. Kakihana, H. Arashi, and M. Yoshimura, J. Phys. Chem. Solids, 1996, 57,17.

13 K. Nomura, Y. Mizutani, M. Kawai, Y. Nakamura, O. Yamamoto, Solid State Ionics, 2000, 132, 235. 
14 V.M. Orera, R.I. Merino, F. Peña, Solid State Ionics, 1994, 72, 224.

15 F. M. Spiridonov, L. N. Popova, R. Ya. Popi'skil, J. Solid State Chem., 1970, 2, 430.

16 G. Xu, Y. W. Zhang, C. S. Liao, C. H. Yan, Phys. Chem. Chem. Phys., 2004, 6, 5410.

17 K. Wurst, E. Schweda, D.J.M. Bevan, J. Mohyla, K.S. Wallwork, M. Hofmann, Solid State Sci., 2003, 5, 1491.

18 F. Tietz, W. Fischer, Th. Hauber, G. Mariotto, Solid State Ion., 1997, 100, 289.

19 H. Fujimori, M. Yashima, M. Kakihana, M. Yoshimura, J. Am. Ceram. Soc., 1988, 81, 2893.

20 H. Fujimori, M. Yashima, M. Kakihana, M. Yoshimura, J. Appl. Phys., 2002, 91, 6493.

21 M. A. Laguna-Bercero, J. A. Kilner and S. J. Skinner, Solid State Ion., doi:10.1016/j.ssi.2010.01.003.

22 K. Ukai, Y. Mizutani, Y. Kume, Electrochem. Soc. Proc., 2001, 16, 375.

23 N. Nicoloso, R.I. Merino, H. Yugami and J. Maier, Electrochem. Soc. Proceedings, 1997, 95-24, 106

24 V.M. Orera, R.I. Merino and Y. Chen, Phys. Rev. B, 1990, 42, 9782

25 R.I. Merino and V.M. Orera, Solid State Ion., 1995, 76, 97

26 J.H. Park and R.N. Blumenthal, J. Electrochem. Soc. 1989, 136, 2867

27 R. Knibbe, M. L. Traulsen, A. Hauch, S. D. Ebbesen, M. Mogensen, J. Electrochem. Soc., 2010, 157, B1209. 
28 M. A. Laguna-Bercero, R. Campana, A. Larrea, J. A. Kilner, V. M. Orera, J. Power Sourc., doi:10.1016/j.jpowsour.2011.01.015

29 J. Cai, C. Raptis, Y.S. Raptis, E. Anastassakis, Phys. Rev., 1995, 51, 201.

30 M. Ishigame, E. Yoshida, Solid State Ion., 1987, 23, 24.

31 R.I. Merino, V.M. Orera, R. Cases and M.A. Chamarro, J. Phys.:Condens. Matter, 1991, 3, 8491.

32 H. Kishimoto, N. Sakai, T. Horita, K. Yamaji, Y.-P. Xiong, M.E. Brito and H. Yokokawa, Solid State Ion., 2008, 179, 2037.

33 H. Fujimori, M. Yashima, M. Kakihana, M. Yoshimura, J. Am. Ceram. Soc., 1998, 81, 2885.

34 S. Lukich, C. Carpenter, N. Orlovskaya, J. Power Sourc., 2010, 195, 2301. 

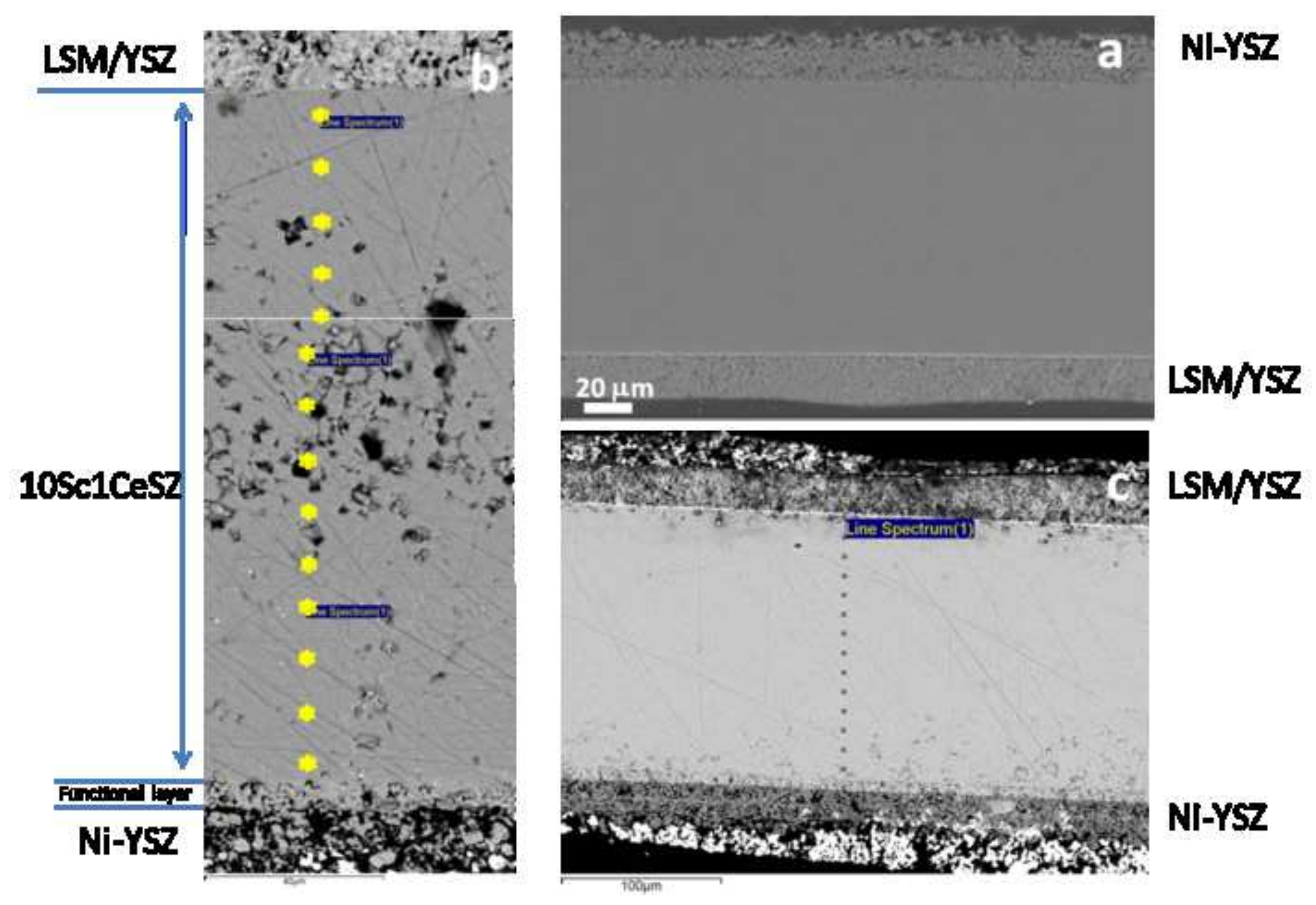

NI-YSZ 


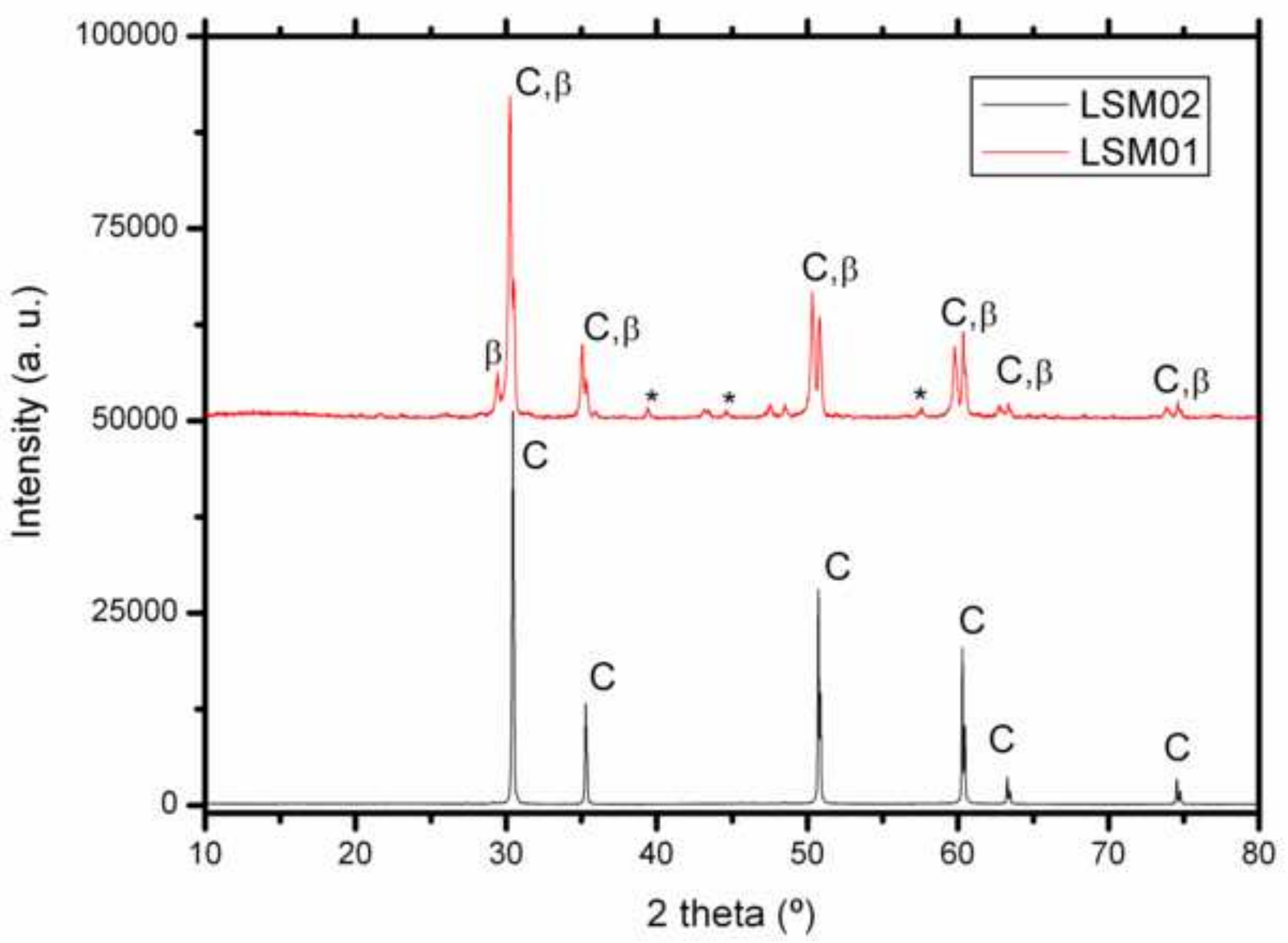




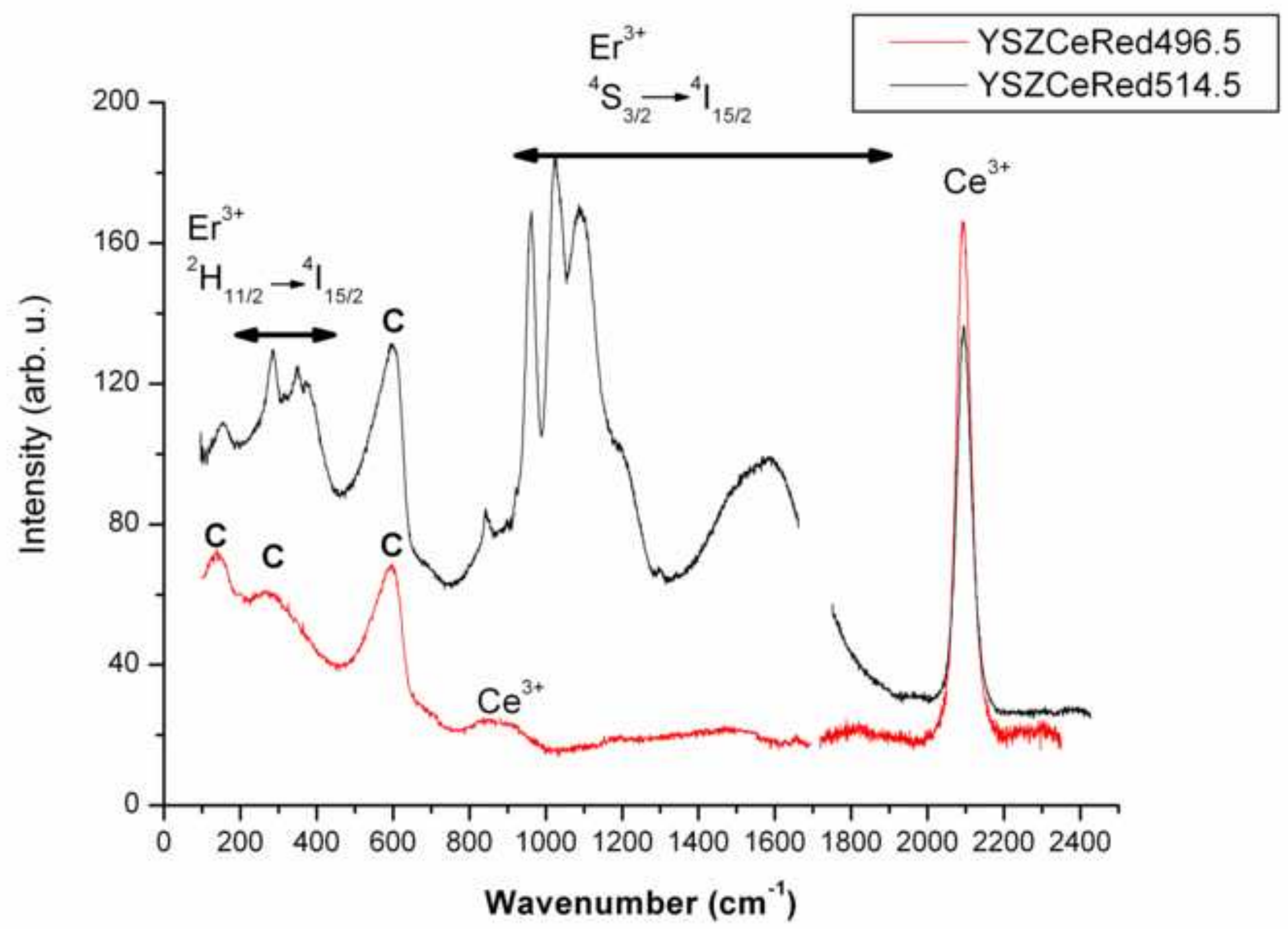




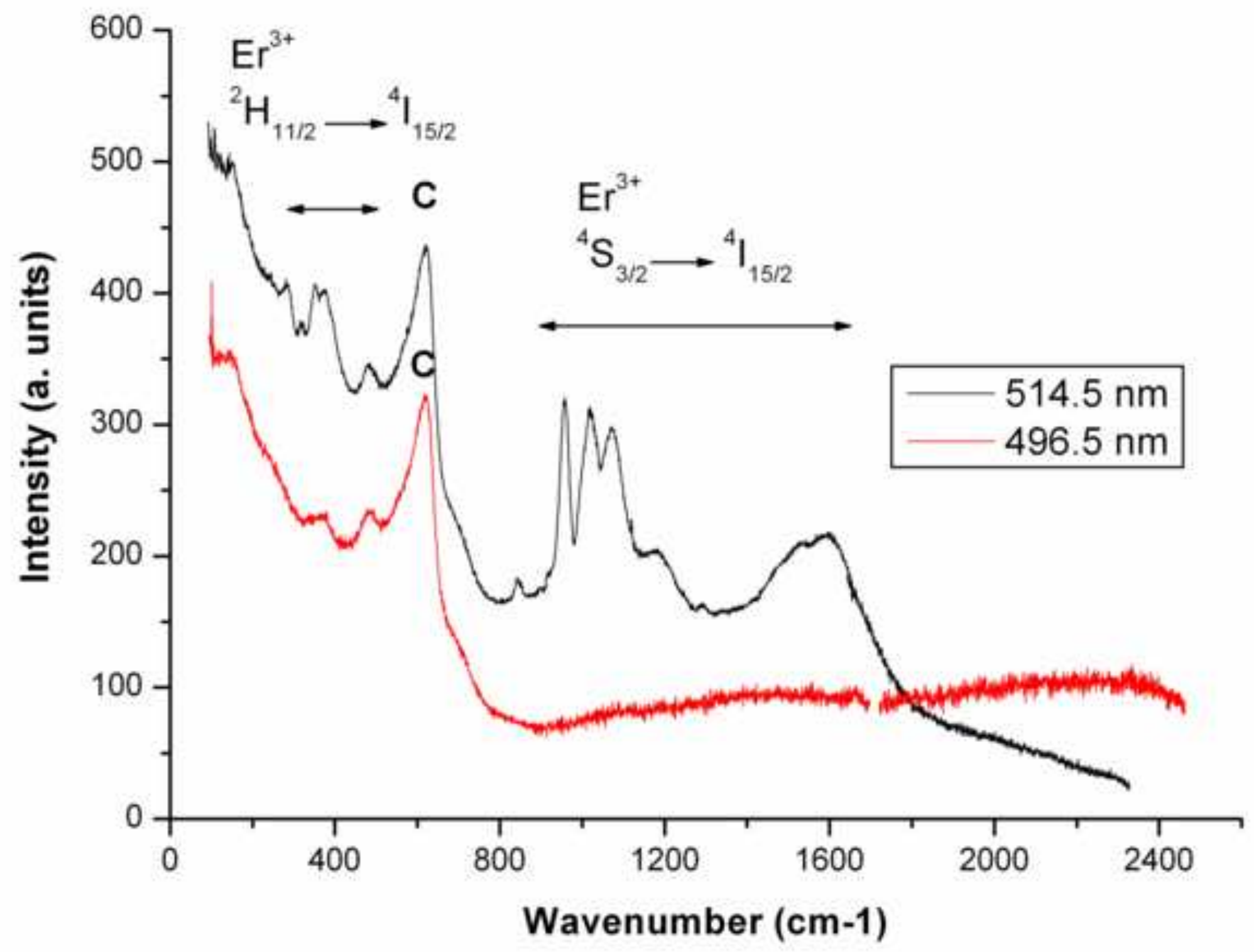




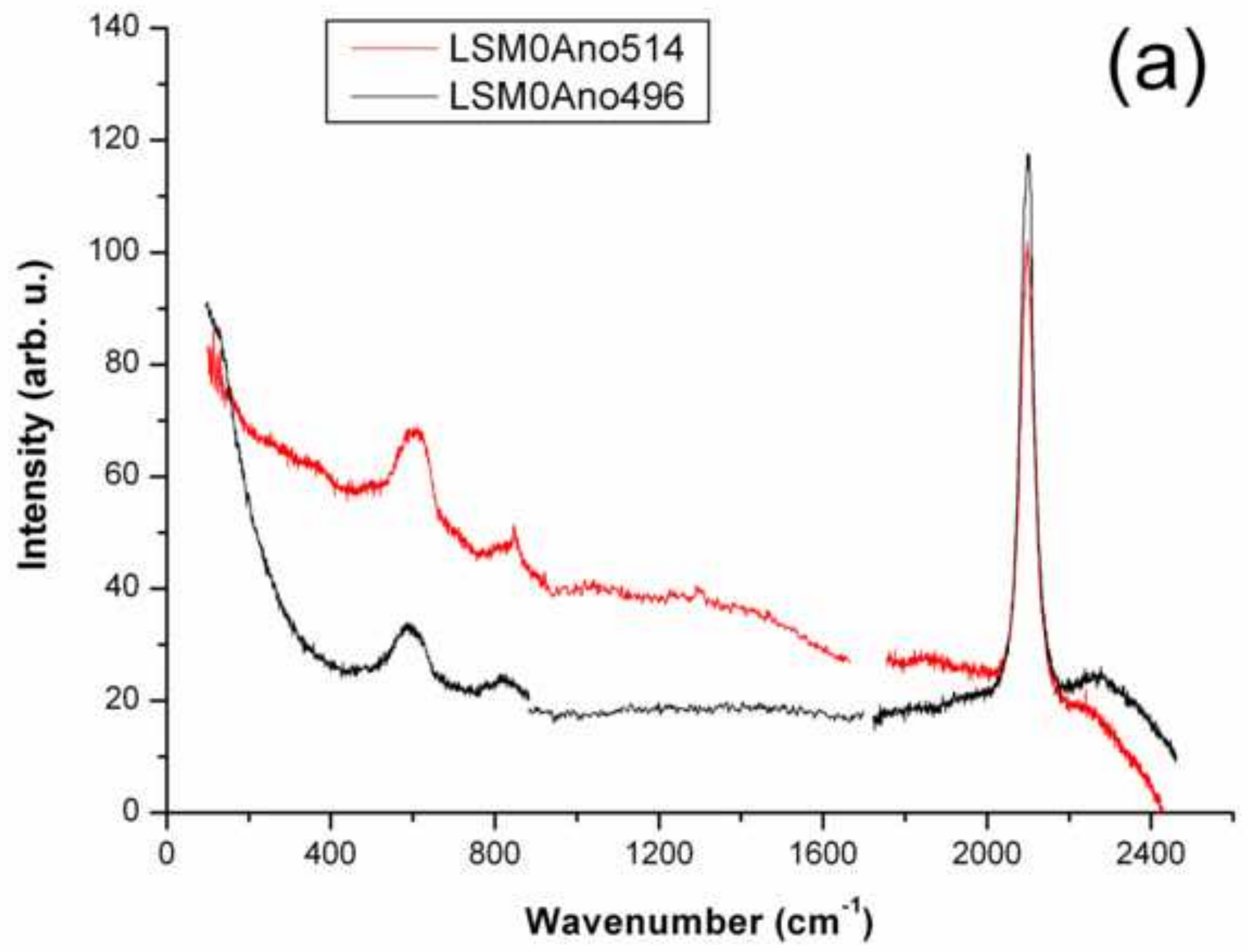




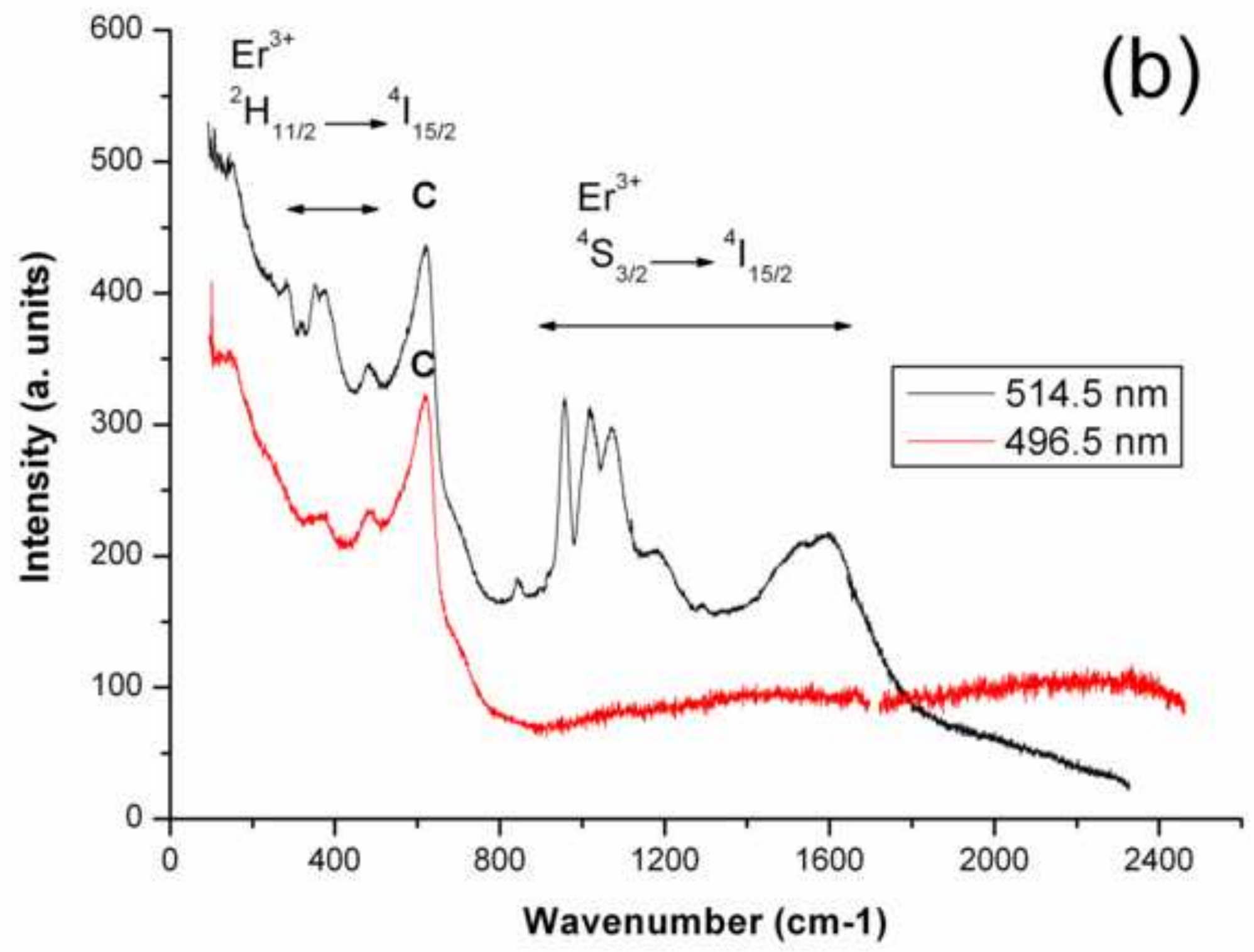




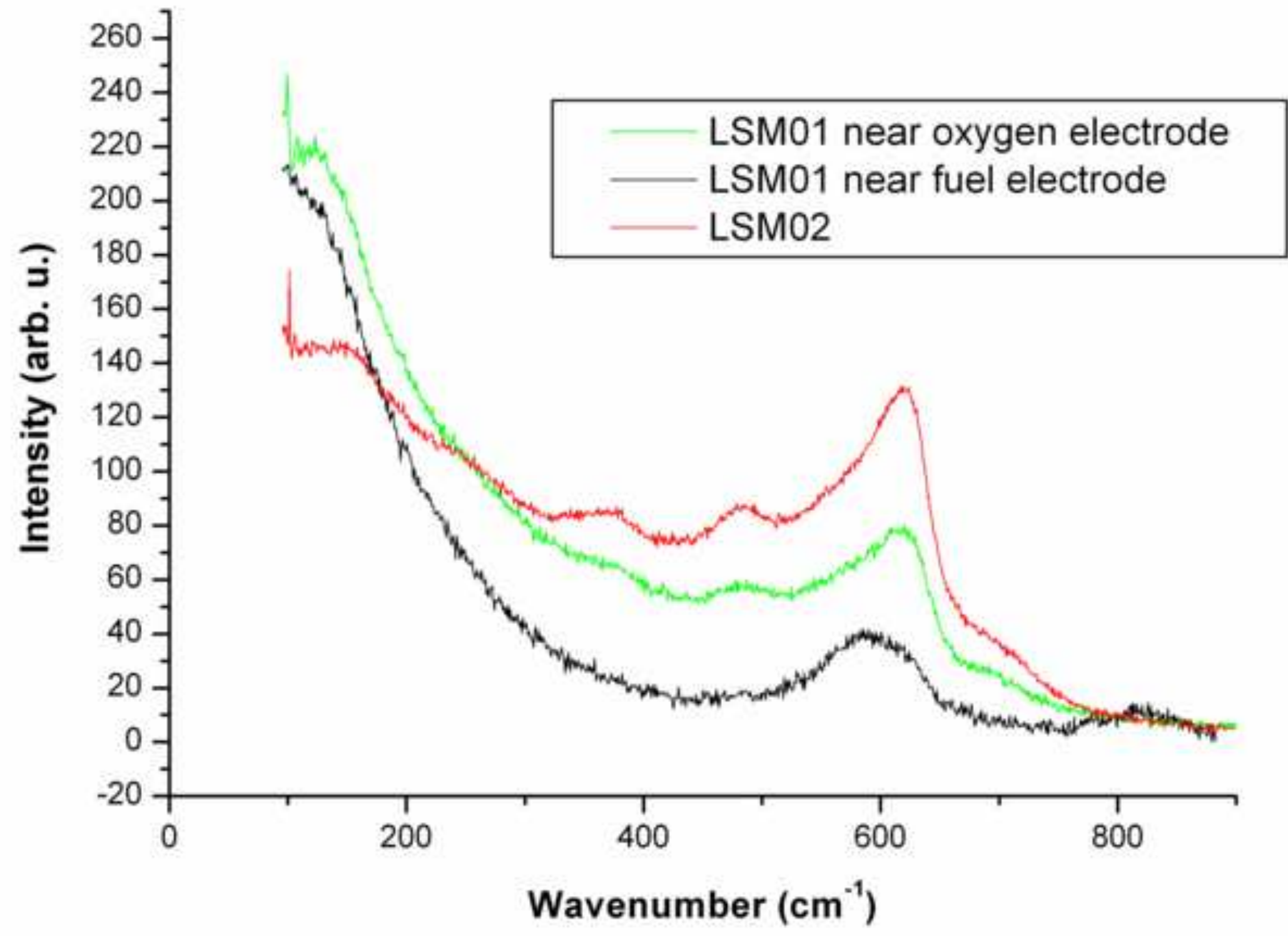




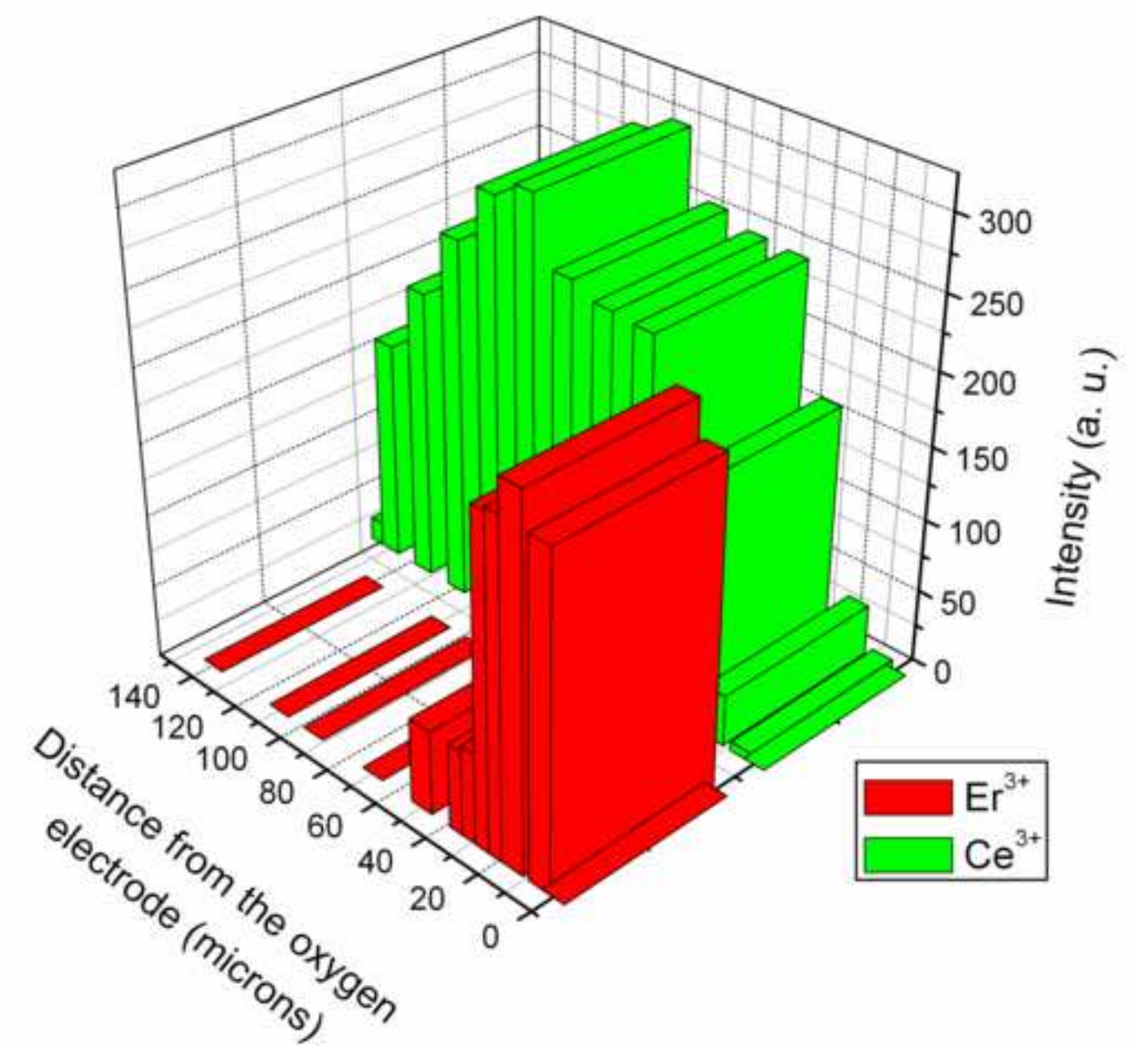

